\title{
Common Variant in GRN Is a Genetic Risk Factor for Hippocampal Sclerosis in the Elderly
}

\author{
Dennis W. Dickson Matthew Baker Rosa Rademakers \\ Department of Neuroscience, Mayo Clinic, Jacksonville, Fla., USA
}

\section{Key Words}

Alzheimer's disease $\cdot$ Hippocampal sclerosis .

Immunohistochemistry · Progranulin gene

\begin{abstract}
Background: Hippocampal sclerosis ( $\mathrm{HpSCl}$ ) is common in elderly subjects with dementia, either alone or accompanied by other pathologic processes. It is also found in $>70 \%$ of frontotemporal lobar degeneration with TDP-43 immunoreactive inclusions (FTLD-TDP). TDP-43 inclusions are detected in $>20 \%$ of Alzheimer disease (AD) and $>70 \%$ of $\mathrm{HpSCl}$ cases. The most common cause of FTLD-TDP is mutation in the progranulin gene (GRN). Recently, a common genetic variant in the $3^{\prime}$ untranslated region (3'UTR) of GRN (rs5848; c. ${ }^{*} 78 \mathrm{C}>\mathrm{T}$ ) located in a microRNA binding site regulated progranulin expression, and the T-allele was increased in FTLDTDP compared to controls. Objective: The goal of this study was to determine if the $3^{\prime} U T R$ variant in GRN was associated with TDP-43 immunoreactivity in AD with and without HpScl. Methods: 644 cases of pathologically confirmed AD, including 57 with $\mathrm{HpScl}$, were screened for TDP-43 immunoreactivity and were genotyped at the GRN 3'UTR single-nucleotide polymorphism rs5848 using previously published methods. Results: There was a trend $(p=0.06)$ for TDP-43 immunoreactivity, but a very significant $(p=0.005)$ association of $\mathrm{HpScl}$ with the variant, with $72 \%$ of $A D$ with $\mathrm{HpScl}$ carrying a T-allele, compared to $51 \%$ of $A D$ without $\mathrm{HpScl}$
\end{abstract}

carrying a T-allele. Conclusion: The results suggest that a genetic variant in GRN leading to decreased levels of progranulin may be a risk factor for $\mathrm{HpScl}$ in $\mathrm{AD}$, while its role in TDP-43 immunoreactivity in AD remains less certain.

Copyright $\odot 2010$ S. Karger AG, Basel

\section{Introduction}

Hippocampal sclerosis ( $\mathrm{HpScl})$ is defined by selective neuronal loss and gliosis in CA1 and subiculum sectors of the hippocampus (fig. 1) [1]. HpScl is common in elderly subjects with dementia, either alone or accompanied by other pathologic processes [2]. It is most often associated with pathologic features of frontotemporal lobar degeneration (FTLD) $[3,4]$ and can be detected in more than $75 \%$ of FTLD cases [5]. One of the first studies to draw attention to $\mathrm{HpScl}$ in the elderly noted it in more than $20 \%$ of demented patients over 80 years of age [1]. The clinical syndrome can be mistaken for amnestic mild cognitive impairment $[6,7]$, a condition thought to represent prodromal Alzheimer's disease (AD) [8], and in some cases it is the only structural abnormality to explain dementia [9]. It is sometimes associated with tauopathy [10] that resembles argyrophilic grain disease, a medial temporal tauopathy that increases in frequency with age [11] and can also present with amnestic mild cognitive impairment [12]. Focal neuronal loss and gliosis in the

\section{KARGER}

(C) 2010 S. Karger AG, Basel

Fax +4161306 1234

E-Mail karger@karger.ch

www.karger.com
Accessible online at:

www.karger.com/ndd
Dennis W. Dickson, MD

Department of Neuroscience, Mayo Clinic

4500 San Pablo Road

Jacksonville, FL 32224 (USA)

Tel. +1 904953 7137, Fax +1 904953 7117, E-Mail dickson.dennis@ mayo.edu 
Fig. 1. $\mathrm{HpScl}$ is characterized by selective neuronal loss in CA1 with relative preservation of neurons in CA3.
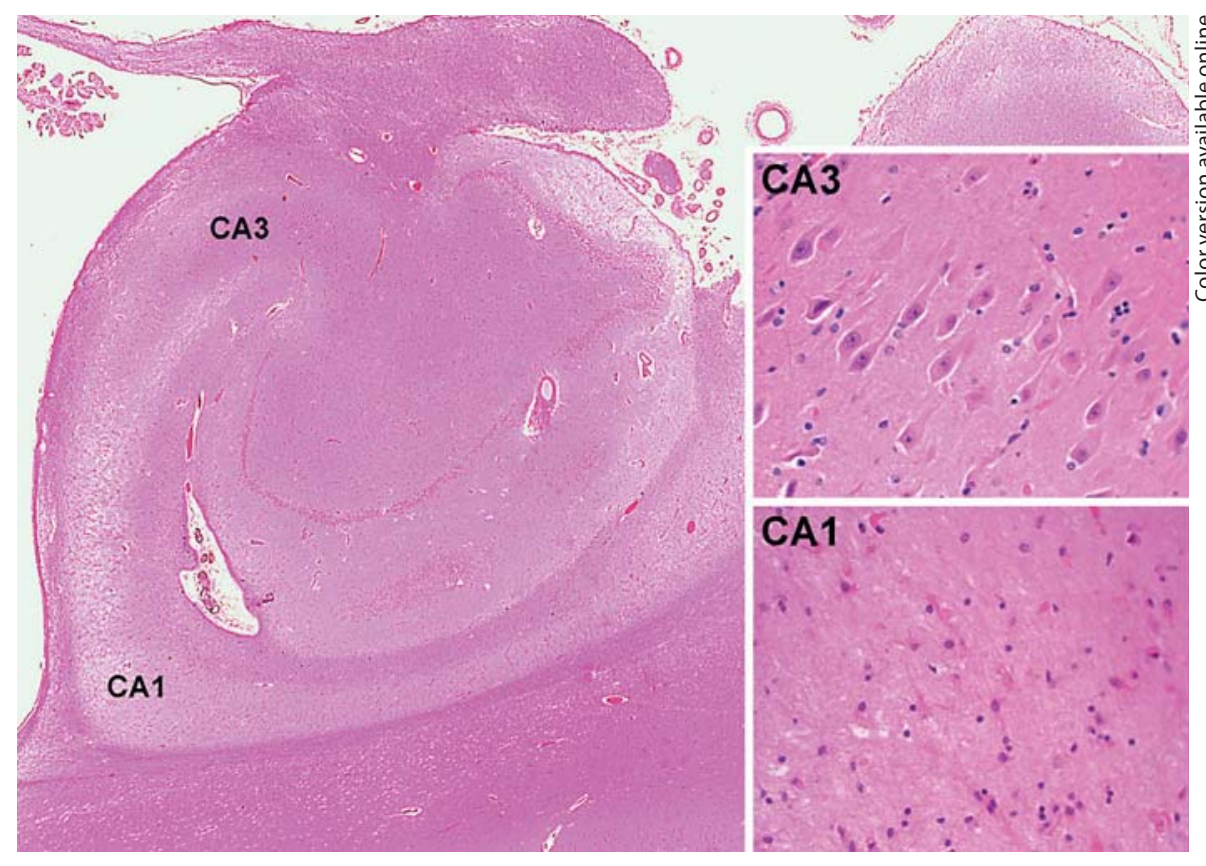

hippocampus can be seen in other degenerative disorders, such as Lewy body disease, but the distribution is different, being most severe in CA2/3 [13, 14].

Immunochemistry using a panel of monoclonal antibodies raised to FTLD brain homogenates led to the discovery of TDP-43 as the major constituent of neuronal inclusions in the most common form of FTLD [15] which is now referred to as FTLD-TDP [16]. TDP-43, for transactivation response protein of 43-kDA molecular weight, is an RNA-binding protein involved in transcriptional regulation that has more recently been implicated in other RNA-dependent cellular functions, such as storage, transport and degradation of mRNA [17]. While initially considered to be a specific marker for FTLD-TDP, this has been called into question as TDP-43 immunoreactivity has been found in $30-50 \%$ of $\mathrm{AD}$ cases $[18,19]$ and most cases of $\mathrm{HpScl}[2,18,20]$.

The most common genetic basis of FTLD-TDP is mutation in the gene for progranulin (GRN) [21-23], and the pathology in all cases associated with pathogenic mutations in GRN is FTLD-TDP [24, 25]. At present, there are over 125 variants reported in GRN, but only 66 that are definitely pathogenic (http://www.molgen.ua.ac.be/ FTDMutations). One of the variants is a single-nucleotide polymorphism (rs5848) in the $3^{\prime}$ untranslated region (3'UTR) of GRN [26]. Previous studies showed that the T-allele of rs5848 in the $3^{\prime} \mathrm{UTR}$ of GRN was associated with FTLD-TDP [26].
Given that most cases of $\mathrm{HpScl}$ are associated with TDP-43 pathology, that many cases of FTLD-TDP have $\mathrm{HpScl}$, and that GRN rs5848 is associated with FTLDTDP, we hypothesized that GRN rs5848 would also be associated with $\mathrm{HpScl}$ found in $\mathrm{AD}$. As a corollary, if TDP-43 pathology in AD is related to a similar disease process as that seen in FTLD-TDP, the GRN rs5848 T-allele might also associate with AD cases that have TDP-43 immunoreactivity. We set out to test these hypotheses by determining the rs5848 genotype in a series of $644 \mathrm{AD}$ cases that were screened for TDP-43 pathology with immunohistochemistry. A subset of cases had HpScl, which would permit assessment of association of GRN rs5848 with $\mathrm{HpScl}$, as well.

\section{Methods}

We obtained frozen brain tissue for DNA extraction and fixed tissue for immunohistochemistry of 644 cases of pathologically confirmed AD. All cases were from the brain bank at Mayo Clinic, Jacksonville and had been evaluated by previously described methods [27]. GRN rs5848 was determined as previously described [26] and TDP-43 immunohistochemistry was also performed as previously described [18]. There were 275 men and 369 women, and the average age at death was $80 \pm 9$ years; $\mathrm{HpScl}$ was detected in 57 cases (9\%). Statistical analysis was carried out with SigmaStat for Windows, version 3.0.1a (Systat Software, Richmond, Calif., USA). A significance level was set at 0.05 . 


\section{Results}

TDP-43 immunoreactivity was detected in 219 (34\%) of the $644 \mathrm{AD}$ cases. It was present in 44 of 57 (77\%) AD cases with $\mathrm{HpScl}$ compared to 175 of 587 (30\%) AD cases without $\mathrm{HpScl}\left(\chi^{2} 49.9, \mathrm{p}<0.001\right)$. Most often, TDP-43 immunoreactivity was detected in neurons in the limbic distribution, with a smaller subset showing more diffuse distribution, similar to results reported previously [18]. TDP-43 immunoreactivity was not significantly associated with concomitant vascular pathology (Spearman $\mathrm{r}=$ 0.052), which was detected in 196 (30\%) of the AD cases, or with Lewy bodies (Spearman $r=0.022$ ), which was detected in 185 (29\%) of the AD cases.

Presence of TDP-43 immunoreactivity in AD correlated with older age (Spearman $r=0.26, p<0.001$ ), female $\operatorname{sex}\left(\chi^{2} \mathrm{p}=0.04\right)$ and presence of $\mathrm{HpScl}\left(\chi^{2} \mathrm{p}<0.001\right)$. A multiple logistic regression analysis showed that age and presence of $\mathrm{HpScl}$ were significant predictors of TDP-43 immunoreactivity (age: OR 1.1, 95\% confidence interval 1.04-1.10; HpScl: OR 7.0, 95\% confidence interval 3.613.6). There was a trend for TDP-43 to be associated with GRN rs5848 T-allele $\left(\chi^{2} \mathrm{p}=0.06\right)$, but when included in a multiple regression analysis with age and $\mathrm{HpScl}$, it was not statistically significant $(\mathrm{p}=0.093)$.

The T-allele of GRN rs5848 was significantly associated with $\mathrm{HpScl}$ in both genotype and allele frequency analyses (table 1). Of the 57 cases of $\mathrm{AD}$ and $\mathrm{HpScl}, 72 \%$ carried a T-allele, while only $51 \%$ of $\mathrm{AD}$ cases without $\mathrm{HpScl}$ had a T-allele. The difference in the frequency of the GRN rs5848 T-allele in $\mathrm{HpScl}$ was greater than chance $(\mathrm{p}=0.005)$. The results suggest that a genetic variant in $G R N$ may be a risk factor for $\mathrm{HpScl}$ in the elderly.

\section{Discussion}

Progranulin is encoded by a single gene on chromosome 17q21 (GRN), and is a 593-amino acid, cysteine-rich protein with an estimated molecular weight of $68.5 \mathrm{kDa}$ that runs at $90 \mathrm{kDa}$ on standard Western blots due to heavy glycosylation [28]. It contains seven granulin-like domains, which consist of highly conserved tandem repeats of a rare 12 cysteinyl motif [29]. Proteolytic cleavage of the precursor protein by extracellular proteases, such as elastase, gives rise to smaller peptide fragments termed granulins [30]. These fragments range in size from 6 to $25 \mathrm{kDa}$ and have been implicated in a range of biological functions, some with properties similar to proinflammatory cytokines [30]. Progranulin plays a role in embry-
Table 1. GRN 3'UTR in AD with and without $\mathrm{HpScl}$

\begin{tabular}{clll}
\hline & HpScl & No HpScl & $\mathrm{p}$ value $\left(\chi^{2}\right)$ \\
\hline $\begin{array}{c}\text { Genotype } \\
\text { rs5848 CC }\end{array}$ & 16 & 286 & 0.020 \\
rs5848 CT & $33(58 \%)$ & $253(43 \%)$ & \\
rs5848 TT & $8(14 \%)$ & $48(8 \%)$ & \\
\hline Allele & & & 0.005 \\
rs5848 C & 65 & 825 & \\
rs5848 T & $49(43 \%)$ & $349(31 \%)$ & \\
\hline
\end{tabular}

onic development, neoplasia, inflammation and wound healing [28], but its function in the central nervous system is not yet understood [31]. It is widely expressed in neurons, glia and endothelial cells. All known mutations in GRN have the same effect; they lead to $50 \%$ decreased expression of progranulin and mediate their effects through this deficiency, a process known as haploinsufficiency. Whether FTLD-TDP is caused by deficiencies in trophic actions of progranulin or cytokine-like properties of granulins, or both, and whether the effects of GRN are primarily on neurons, glia or endothelial cells is unknown, but these are areas of active investigation.

An emerging topic in the genetics of neurodegenerative diseases is that rare variants in genes (i.e. mutations) cause rare familial forms of the disease, but common variants in the same genes may contribute to risk for the disease in common nonfamilial forms of the disease. A number of examples can be cited, i.e. mutations in SNCA cause rare familial Parkinson disease [32], while common variants in SNCA are a risk factor for common nonfamilial Parkinson disease [33]. Variants in GRN are thus candidate genetic risk factors for nonfamilial forms of FTLDTDP. Of more that 125 variants described in GRN, only 66 segregate with disease (http://www.molgen.ua.ac.be/ FTDMutations). One of these variants is located in the 3'UTR of GRN with a sequence consistent with a microRNA binding site [26], and it is associated with sporadic FTLD-TDP [26].

Recent research has drawn attention to the role of diverse functions of small RNAs, in particular a specific subclass of small RNAs, microRNAs, which have the ability to regulate gene translation through repression or promoting messenger RNA cleavage $[34,35]$. At present, there are 851 known microRNAs in humans (http:// microrna.sanger.ac.uk) and many target genes, including GRN. The GRN sequence has at least one micro-RNA binding site for miR-659, a micro-RNA that is expressed 
in the brain [26]. In addition to GRN, there are 974 other targets of miR-659 (http://microrna.sanger.ac.uk). The presence of the T-allele at the 3'UTR in GRN favors miR659 binding, which lowers levels of progranulin expression without affecting the level of messenger RNA for progranulin. The levels of progranulin in the brains of individuals homozygous for the T-allele are intermediate between wild type (CC homozygous) and individuals carrying a disease-causing mutation in GRN [26]. Similar studies have yet to be performed in AD with TDP-43 immunoreactive inclusions or with $\mathrm{HpScl}$.

The association of the rs5848 T-allele with FTLD-TDP suggests that lower progranulin levels may be one of the factors associated with risk of disease. Similarly, in this study we showed that the T-allele was overrepresented in AD cases with $\mathrm{HpScl}$, most of which (77\%) had TDP-43 immunoreactivity, which suggests that GRN may also be a risk factor for $\mathrm{HpScl}$. The findings further indicate that $\mathrm{HpScl}$ in AD is not merely a reflection of severe neuronal loss due to $\mathrm{AD}$, but rather neuronal loss due to a different mechanism, and perhaps analogous to the mechanism of neuronal loss in FTLD-TDP [36]. While there was a trend for the T-allele to be overrepresented in $\mathrm{AD}$ cases with TDP-43 immunoreactive inclusions, in a multivariate analysis this association was lost when $\mathrm{HpScl}$ cases were excluded. In addition to $\mathrm{HpScl}$, advanced age was a risk factor for TDP-43 immunoreactivity in AD. The explanation for the age association is not clear at this time.

Selective neuronal loss in the same distribution as that seen in $\mathrm{HpScl}$ is also a feature of hypoxic-ischemic injury to the hippocampus. It was of interest that while there was no association of TDP-43 immunoreactivity with vascular pathology, there was a weak association of $\mathrm{HpScl}$ with vascular pathology (Spearman $r=0.091, p=0.021$ ). This may indicate that a subset of $\mathrm{HpScl}$ in $\mathrm{AD}$ may be related to hypoxic ischemic injury [2]. In this series of $\mathrm{AD}$ cases, 196 had concomitant vascular pathology with $\mathrm{HpScl}$ in 25 cases, 21 of which had TDP-43 immunoreactivity. The 4 cases without TDP-43 immunoreactivity are likely to be those in which hypoxic-ischemic factors may have contributed to hippocampal neuronal loss.

\section{Acknowledgements}

This study was supported by NIH grants P50-NS40256, P01AG03949, P50-AG16574 and P50-AG25711.

\section{References}

1 Dickson DW, Davies P, Bevona C, et al: Hippocampal sclerosis: a common pathological feature of dementia in very old $(>$ or $=80$ years of age) humans. Acta Neuropathol 1994;88:212-221.

$\checkmark 2$ Zarow C, Sitzer TE, Chui HC: Understanding hippocampal sclerosis in the elderly: epidemiology, characterization, and diagnostic issues. Curr Neurol Neurosci Rep 2008;8: 363-370.

-3 Hatanpaa KJ, Blass DM, Pletnikova O, et al: Most cases of dementia with hippocampal sclerosis may represent frontotemporal dementia. Neurology 2004;63:538-542.

4 Blass DM, Hatanpaa KJ, Brandt J, et al: Dementia in hippocampal sclerosis resembles frontotemporal dementia more than Alzheimer disease. Neurology 2004;63:492497.

5 Josephs KA, Dickson DW: Hippocampal sclerosis in tau-negative frontotemporal lobar degeneration. Neurobiol Aging 2007;28: 1718-1722.

-6 Petersen RC, Parisi JE, Dickson DW, et al: Neuropathologic features of amnestic mild cognitive impairment. Arch Neurol 2006;63: 665-672.
7 Sepe-Monti M, De Carolis A, Bomboi G, Castri P, Giubilei F: MRI evidence of bilateral hippocampal sclerosis in amnestic mild cognitive impairment. Eur J Neurol 2006;13: 1031-1032.

-8 Kantarci K, Petersen RC, Przybelski SA, et al: Hippocampal volumes, proton magnetic resonance spectroscopy metabolites, and cerebrovascular disease in mild cognitive impairment subtypes. Arch Neurol 2008;65: 1621-1628.

-9 Ala TA, Beh GO, Frey WH 2nd: Pure hippocampal sclerosis: a rare cause of dementia mimicking Alzheimer's disease. Neurology 2000;54:843-848.

$\checkmark 10$ Beach TG, Sue L, Scott S, et al: Hippocampal sclerosis dementia with tauopathy. Brain Pathol 2003;13:263-278.

11 Togo T, Sahara N, Yen SH, et al: Argyrophilic grain disease is a sporadic 4-repeat tauopathy. J Neuropathol Exp Neurol 2002;61: 547-556.

12 Jicha GA, Petersen RC, Knopman DS, et al: Argyrophilic grain disease in demented subjects presenting initially with amnestic mild cognitive impairment. J Neuropathol Exp Neurol 2006;65:602-609.
13 Obi T, Nishioka K, Ross OA, et al: Clinicopathologic study of a SNCA gene duplication patient with Parkinson disease and dementia. Neurology 2008;70:238-241.

14 Farrer M, Kachergus J, Forno L, et al: Comparison of kindreds with parkinsonism and alpha-synuclein genomic multiplications. Ann Neurol 2004;55:174-179.

15 Neumann M, Sampathu DM, Kwong LK, et al: Ubiquitinated TDP-43 in frontotemporal lobar degeneration and amyotrophic lateral sclerosis. Science 2006;314:130-133.

16 Mackenzie IR, Neumann M, Bigio EH, et al: Nomenclature for neuropathologic subtypes of frontotemporal lobar degeneration: consensus recommendations. Acta Neuropathol 2009;117:15-18.

17 Wang IF, Wu LS, Shen CK: TDP-43: an emerging new player in neurodegenerative diseases. Trends Mol Med 2008;14:479-485.

18 Amador-Ortiz C, Lin WL, Ahmed Z, et al: TDP-43 immunoreactivity in hippocampal sclerosis and Alzheimer's disease. Ann Neurol 2007;61:435-445.

19 Hasegawa M, Arai T, Nonaka T, et al: Phosphorylated TDP-43 in frontotemporal lobar degeneration and amyotrophic lateral sclerosis. Ann Neurol 2008;64:60-70. 
20 Probst A, Taylor KI, Tolnay M: Hippocampal sclerosis dementia: a reappraisal. Acta Neuropathol 2007;114:335-345.

-21 Baker M, Mackenzie IR, Pickering-Brown $\mathrm{SM}$, et al: Mutations in progranulin cause tau-negative frontotemporal dementia linked to chromosome 17. Nature 2006;442: 916-919.

>2 Cruts M, Gijselinck I, van der Zee J, et al: Null mutations in progranulin cause ubiquitin-positive frontotemporal dementia linked to chromosome 17q21. Nature 2006;442: 920-924.

23 Gass J, Cannon A, Mackenzie IR, et al: Mutations in progranulin are a major cause of ubiquitin-positive frontotemporal lobar degeneration. Hum Mol Genet 2006;15:29883001 .

24 Josephs KA, Ahmed Z, Katsuse O, et al: Neuropathologic features of frontotemporal lobar degeneration with ubiquitin-positive inclusions with progranulin gene (PGRN) mutations. J Neuropathol Exp Neurol 2007; 66:142-151.
25 Mackenzie IR, Baker M, Pickering-Brown S, et al: The neuropathology of frontotemporal lobar degeneration caused by mutations in the progranulin gene. Brain 2006;129:30813090.

26 Rademakers R, Eriksen JL, Baker M, et al Common variation in the miR- 659 bindingsite of GRN is a major risk factor for TDP43 positive frontotemporal dementia. Hum Mol Genet 2008;17:3631-3642.

27 Luis CA, Barker WW, Gajaraj K, et al: Sensitivity and specificity of three clinical criteria for dementia with Lewy bodies in an autopsy-verified sample. Int J Geriatr Psychiatry 1999;14:526-533.

28 He Z, Bateman A: Progranulin (granulinepithelin precursor, PC-cell-derived growth factor, acrogranin) mediates tissue repair and tumorigenesis. J Mol Med 2003;81:600612.

29 Bhandari V, Palfree RG, Bateman A: Isolation and sequence of the granulin precursor cDNA from human bone marrow reveals tandem cysteine-rich granulin domains. Proc Natl Acad Sci USA 1992;89:17151719.
30 Bateman A, Belcourt D, Bennett H, Lazure C, Solomon S: Granulins, a novel class of peptide from leukocytes. Biochem Biophys Res Commun 1990;173:1161-1168.

-31 Ahmed Z, Mackenzie IR, Hutton ML, Dickson DW: Progranulin in frontotemporal lobar degeneration and neuroinflammation. J Neuroinflammation 2007;4:7.

32 Polymeropoulos MH, Lavedan C, Leroy E, et al: Mutation in the alpha-synuclein gene identified in families with Parkinson's disease. Science 1997;276:2045-2047.

-33 Maraganore DM, de Andrade M, Elbaz A, et al: Collaborative analysis of alpha-synuclein gene promoter variability and Parkinson disease. JAMA 2006;296:661-670.

>34 He L, Hannon GJ: MicroRNAs: small RNAs with a big role in gene regulation. Nat Rev Genet 2004;5:522-531.

35 Carthew RW, Sontheimer EJ: Origins and mechanisms of miRNAs and siRNAs. Cell 2009; 136:642-655.

36 Dickson DW: TDP-43 immunoreactivity in neurodegenerative disorders: disease versus mechanism specificity. Acta Neuropathol 2008; 115:147-149. 